\title{
Sewer asset management planning - implementation of a structured approach in wastewater utilities
}

\author{
M.A. Cardoso, M.C. Almeida and M. Santos Silva \\ Hydraulics and Environment Department, LNEC- National Civil Engineering Laboratory, Lisbon, Portugal
}

\begin{abstract}
Wastewater services are fundamental for the protection of public health and environment, population wellbeing and sustainable development of communities. The value of urban water assets represents a major part of all public infrastructures. These assets must be managed rationally and efficiently, justifying investment priorities in a clear and straightforward way. Effective decision-making requires a comprehensive approach allowing the incorporation of desired performance at acceptable risk levels, considering investment and operational costs. Advanced sewer infrastructure asset management (IAM) is key to achieve and ensure adequate future levels of service, in issues such as flooding of urban areas, pollution prevention, balancing performance, risk and cost. The paper illustrates the integration of different support tools and methods by implementation of the AWARE-P procedure for planning IAM, demonstrated by the experience of fourteen wastewater utilities. Results showed the effectiveness of the tools and methods at different stages of the AWARE-P methodology.
\end{abstract}

\section{ARTICLE HISTORY}

Received 15 May 2014 Accepted 27 June 2015

\section{KEYWORDS}

Infrastructure asset management; sewer systems; planning

\section{Introduction}

Wastewater services are essential for the protection of public health, population well-being, sustainable development of communities and environmental protection (CEN, 2008; ISO, 2007a, 2007b, 2007c). These services are strategic, of large socioeconomic relevance and the value of urban water assets represents a major share of public infrastructures. The prevailing low levels of rehabilitation of urban water infrastructures worldwide are a major threat to the long-term sustainability of urban water services. There is a growing focus on the best ways to finance and implement improvements in operation, maintenance and rehabilitation of systems (OECD, 2007).

Utility managers must cope with several challenges, including public health and safety, climate change effects, increasing society expectations, asset deterioration and incorporation of technological developments. It is essential that infrastructures are managed rationally and efficiently, justifying in a clear and straightforward way the investment priorities (Alegre et al., 2011). Restrictions on the use of resources impose increasingly effective and efficient maintenance practices. Advanced infrastructure asset management (IAM) is crucial to achieve and sustain adequate levels of service in the future, for issues such as flooding of urban areas, use of natural resources and prevention of pollution.

Significant research and developments have been carried out in the last decades on IAM methods and tools with different scopes and focus (Alegre, 2007; Ana \& Bauwens, 2010; Fenner, 2000; Halfawy, 2008; INGENIUM \& IPWEA, 2006; Saegrov, 2005,
2006; Schulting \& Sneesby, 2010; Vanier, 2001). However, the need for developments that allow the coherent integration of all the relevant topics of IAM and that can be effectively used for comprehensive planning by the utilities was identified.

Planning needs to incorporate coherently long, mid and shortterm analysis, for the management of the urban water assets, while balancing performance, risk and cost dimensions (Alegre et al., 2011; Brown \& Humphrey, 2005, Baur \& Herz, 2001). Consequently effective decision-making requires a comprehensive approach ensuring the desired performance at an acceptable risk level, taking into consideration the costs of building, operating, maintaining and disposing of capital assets. Available tools support development and solutions in specific themes but do not comprehensively incorporate all the fundamental aspects for IAM planning referred to.

A structured approach for supporting strategic urban water IAM has been developed in the scope of the AWARE-P project (Alegre et al., 2011; www.aware-p.org), an international R\&D effort with strong involvement of Portuguese water utilities partners (Cardoso et al., 2012). It was followed by an implementation stage with an effective, on-field development and implementation of IAM plans by over 30 utilities that have produced their strategic and tactical IAM plans based on the AWARE-P methodology (Leitão et al., 2014).

This paper illustrates the integration of diverse support tools and methods by implementation of the AWARE-P procedure for planning IAM, demonstrated by the experience of fourteen wastewater utilities, focusing on two particular case studies. Results 
showed the effectiveness in the use of the tools and methods at different stages of the AWARE-P methodology. Benefits and drawbacks of the methodology are presented.

\section{Methodology and tools}

\subsection{AWARE-P methodology}

The AWARE-P methodology integrates the principles generally recommended and adopted for IAM planning (INGENIUM \& IPWEA, 2006; Saegrov, 2005, 2006; Sneesby, 2010). It approaches IAM based on PDCA (Plan-Do-Check-Act) principles and requiring full alignment between strategic objectives and targets, and the actual priorities and actions implemented as recommended by ISO 55000/55001/55002 standards (ISO, 2012a, 2012b, 2012c). Urban water infrastructures have system behaviour, meaning that individual components are not independent from one another, and, as a whole, infrastructure functions need to be maintained. System components have a finite life but the system cannot be replaced in its entirety, only piecemeal (Burns et al., 1999). The aim is to ensure system performance as a whole, which is considered in this approach.

Given a set of previously-defined objectives and targets, the AWARE-P methodology provides a standardized assessment of systems as well as of comparison of intervention alternatives considering performance, cost and risk perspectives over the analysis horizon (Alegre et al., 2011; Cardoso et al., 2012; Marques et al., 2011).

This IAM approach is addressed at different planning decision levels (Alegre et al., 2011): strategic, driven by corporate and longterm views, aimed at establishing and communicating strategic priorities to staff and citizens; tactical, where the intermediate managers in charge of the infrastructures need to select the best medium-term solutions; and operational, where the short-term actions are planned and implemented. At each management and planning level, a structured loop (Figure 1) is proposed comprising the following stages: (i) definition of objectives, assessment criteria, metrics and targets, (ii) diagnosis, (iii) plan production, (iv) plan implementation and (v) monitoring and review.

The alignment between the planning levels is thus ensured meaning that the decisions on short-term actions to be implemented contribute to the utility strategic objectives fulfilment.

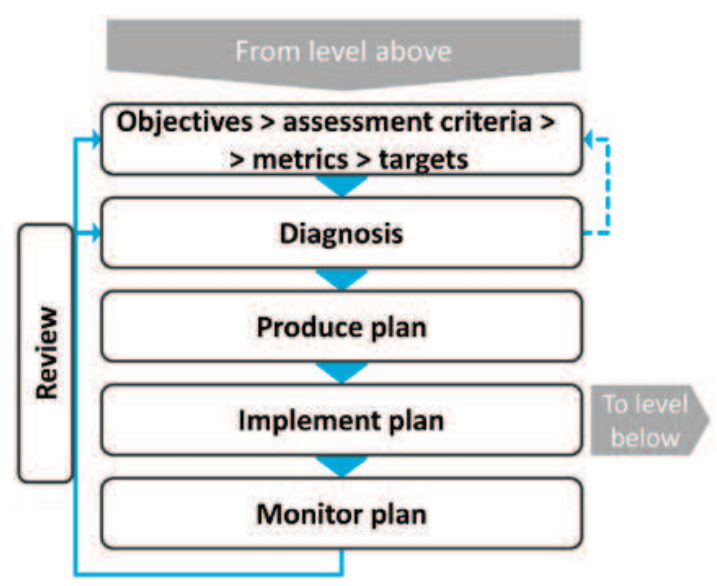

Figure 1. Planning process - at each planning level (Alegre et al., 2011).

\subsection{AWARE-P tools applied}

\subsubsection{Overview}

IAM requires many inputs from different sources and processes: a fragmented landscape of information systems (IS); utility GIS; maintenance management and work order's systems; enterprise resource planning systems; customer and billing; engineering analysis tools such as simulation models, system monitoring and inspection. Within the scope of IAM, mathematical modelling of sewer systems is a powerful tool that provides a detailed hydraulic analysis of the systems. It can bring additional information on the systems' behaviour allowing utilities to improve the knowledge on their performance for different operational conditions, scenarios and alternative solutions (Waslki et al., 2007). Sewer systems inspection provides detailed structural information of the systems, improving the utility's knowledge on their condition.

These processes involve a great variety of utility personnel, from infrastructure asset and maintenance managers, to engineering planners, information system and finance managers. If not properly managed these processes may add dispersion or redundancy of data, processes, objectives and decisions. Efficient IAM should assist data, processes, objectives and decisions integration, in aligning strategic, tactical and operational efforts (Coelho et al., 2013).

The AWARE-P planning software is a tool that was developed to support the methodology application, further to the existing sewer system's analysis tools. It is a web-based environment that integrates data, processes, objectives, metrics and decisions, with the capability to assess and account for individual as well as system behaviour. Currently, for sewer systems, it offers the ability to integrate available data and information from different sources and processes relevant to the IAM decision-making process, including maps, GIS layers and geodatabases; inventory records; work orders maintenance, inspections/CCTV records; performance indicators and asset valuation records. The adequacy and quality of data are fundamental to cost-effective decision making (Price \& Vojinovic, 2011). Thus, quality of the AWARE-P planning results depends on the quality of the input data. Uncertainty associated with the use of specific engineering analysis tools must be considered. AWARE-P allows the incorporation of uncertainty in the decision through the definition of the classification functions for the metrics and the establishment of assessment scenarios.

To support decisions, the software provides an organized framework, which is objective and metric driven, for evaluating and comparing planning alternatives or competing IAM solutions, through traceable and documented performance, risk and cost assessment metrics. These alternatives can be either infrastructural such as sewer rehabilitation, or operation and maintenance such as changes in operation practices, or in sewer cleaning routines. Following the AWARE-P IAM approach, the software seeks to provide support in the alignment and integration of all efforts that may reflect on the infrastructure itself and on the data and information available about it, striving for measurable long-term infrastructural sustainability (Coelho et al., 2013).

Implementation of this methodology requires considerable effort and resources, particularly in cases where there is insufficient integration between different organizational levels (e.g. top 
management decision, technical, operational, poor availability of data (e.g. infrastructure, operation), poor information on system reliability (e.g. failure data, historical records), poor quality of data, limitations in existing information systems, financial constraints.

The software comprises a growing, modular portfolio of system metrics and network analysis tools that may equally be used individually for diagnosis. Table 1 presents the tactical planning stages and the corresponding tools applied to support their development. In this section only the tools that were applied are presented.

\subsubsection{PI tool-performance indicators}

PI tool is an objective-driven environment for selection and calculation of performance indicators (PI), a quantitative assessment of the efficiency or effectiveness of a system, based on standardized, reference PI libraries as well as user-developed or customized ones. Available libraries include the IWA wastewater PI libraries (Alegre et al., 2010; Matos et al., 2003).

2.2.2.1. Risk metrics. The risk metrics applied were calculated based on a risk matrix (Figure 2), also known as a probabilityconsequence matrix (Almeida et al., 2011; Marques et al., 2011). Both the probability of collapse and the consequence were classified considering a scale from 1 to 5 . Risk was classified considering a three classification scale: low, moderate and high.

Probability was estimated based on the structural condition classification following the Water Research Centre method (WRc, 2001). Data from CCTV inspections is coded according to EN 13 508-2:2003 + A1 and this method assigns a score to each sewer depending on observations from sewer inspection. The score is converted into the following classes of structural condition: 1 (good structural condition), 2 (minimal probability of collapse), 3 (unlikely collapse in the near future), 4 (likely to collapse in the near future) and 5 (collapsed or imminent collapse).

\subsubsection{IVI - infrastructure value index}

IVI calculates the infrastructure value index, representing the devaluation degree of an infrastructure, through the ratio between the current value and the replacement value of the infrastructure (Alegre et al., 2014) and should ideally be close to 0.5 . It represents an average age of the system. Values close to 1 mean that the infrastructure is new and does not need rehabilitation. Values below 0.2 mean that the average age of the system is high and significant investment in rehabilitation is needed (Almeida \& Cardoso, 2010).

\subsubsection{PLAN-decision-making}

PLAN embodies the central planning framework, where alternatives (e.g. different subsystems) or competing solutions (e.g. sewer pipe replacement, storage tank construction, sewer cleaning routines) are measured up and compared through selected performance, risk and cost metrics, through interactive numerical 2D/3D graphical information display. The tool is based on three main axes that characterize the assessment and comparison exercise: a set of alternatives, a set of standardized metrics and a given time frame. The latter comprehends a number of user-specified time steps and may include both a planning horizon (i.e., the time frame of the intervention) and an analysis horizon (a longer time frame for impact assessment) (Coelho et al., 2013).

As defined by the user, the selected metrics may come from the performance, risk and cost assessment tools present in the AWARE-P portfolio, or from other complementary technical approaches, such as assessments from system monitoring, mathematical modelling or inspection. The metrics are standardized as numerical indices and then categorized as colour-coded levels (green-good, yellow-adequate and red-deficient levels), on a coherent classification by the user. The target category values are assigned for each metric as reference values to define a classification function, as presented in Figure 3 for the metric Flooding from sewers ( $\mathrm{n} \% 1000$ service connections).

Table 1. Planning stages and supporting AWARE-P software tools.

Planning stages
(i) Tactical objectives and assessment system Objectives, assessment criteria and
metrics aligned with the strategic plan
(ii) Diagnosis: comparisonAsses compare and prioritize amongst systems areas of
analysis
(ii) Diagnosis: detailed In each area of analysis is required a detailed diagnosis
(iii) Plan production: tactics definitionlntervention actions intended to solve
problems identified in the detailed diagnosis

\begin{tabular}{|c|c|c|c|c|c|}
\hline \multirow[b]{2}{*}{ Probability } & \multicolumn{5}{|c|}{ Consequence } \\
\hline & $\begin{array}{c}1: \\
\text { insignificant }\end{array}$ & $\begin{array}{l}2: \\
\text { low }\end{array}$ & $\begin{array}{c}\text { 3: } \\
\text { moderate }\end{array}$ & $\begin{array}{c}4: \\
\text { high }\end{array}$ & $\begin{array}{c}5: \\
\text { very high }\end{array}$ \\
\hline $\begin{array}{l}\text { 1: rare } \\
2 \text { : unlikely }\end{array}$ & low & & & & \\
\hline $\begin{array}{l}\text { 3: moderate } \\
\text { 4: likely } \\
\text { 5: almost certain }\end{array}$ & & & moderate & & high \\
\hline
\end{tabular}

Figure 2. Risk matrix (Almeida et al., 2011). 

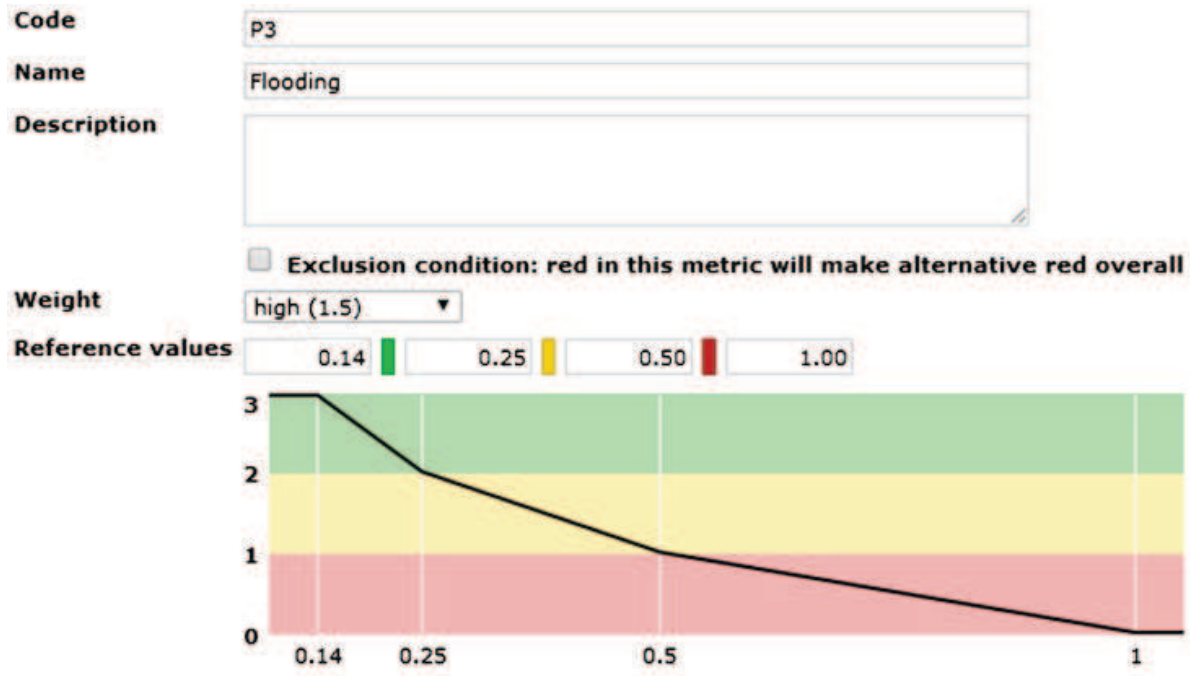

Custom yearly weight/importance

Figure 3. Classification function.

The PLAN tool provides a ranking of the alternative classifications based on the metrics and reference values. The ranking is obtained from the weighted average of the metrics normalized values.

\section{Cases studied}

\subsection{Overview}

Within the projects $i G P I$ - a national initiative for IAM (Leitão et al., 2014) and AWARE-P (Alegre et al., 2011; Cardoso et al., 2012), fourteen Portuguese wastewater utilities developed IAM plans for sewer systems through the implementation of the AWARE-P methodology (Section 2.1), namely in the strategic and tactical decision levels of planning. These utilities were diverse, as described in Figure 4, in terms of served population, service provided, type of systems, management models (e.g. municipal, concession) and different levels of maturity regarding information availability, technical sophistication and management processes implemented.

At the strategic planning level, utilities established the strategies based on the diagnosis results grounded on the objectives defined and on a SWOT analysis (strengths, weaknesses, opportunities and threats).

Given the wide scope of the strategic level of planning, many similarities were identified among the fourteen utilities. The

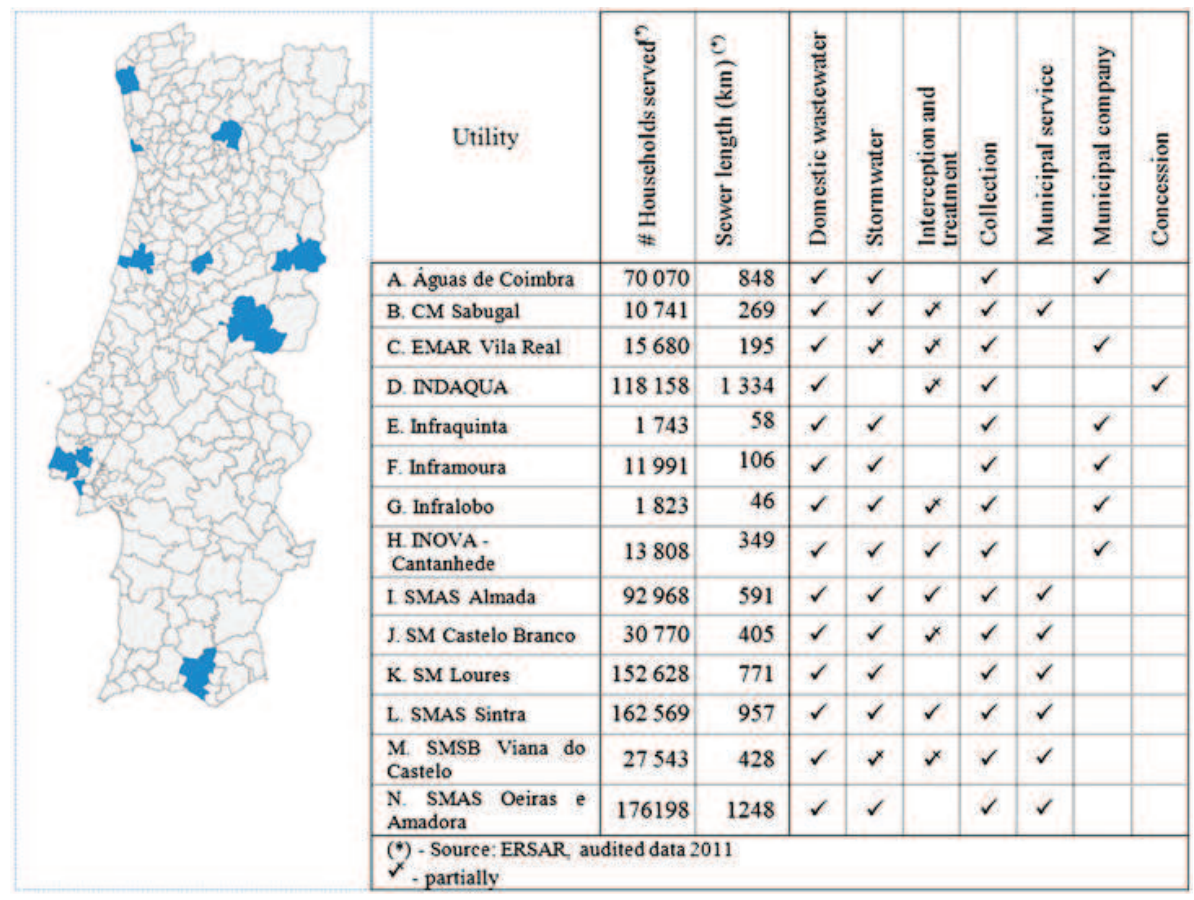

Figure 4. Wastewater utilities that implemented IAM plans for sewers systems. 
Table 2. SWOT analysis aspects identified by fourteen wastewater utilities.

\begin{tabular}{|c|c|c|c|}
\hline Strengths & Utilities & Weaknesses & Utilities \\
\hline $\begin{array}{l}\text { - Good set of technological tools to } \\
\text { assist IAM }\end{array}$ & $A ; C ; I ; J ; K ; L ; M ; N$ & $\begin{array}{l}\text { - Insufficient historical records con- } \\
\text { cerning infrastructure's operation and } \\
\text { maintenance }\end{array}$ & $A ; D ; F ; G ; H ; J ; M ; N$ \\
\hline $\begin{array}{l}\text { - Know-how and strong competence of } \\
\text { human resources }\end{array}$ & $\mathrm{A} ; \mathrm{B} ; \mathrm{D} ; \mathrm{E} ; \mathrm{F} ; \mathrm{G} ; \mathrm{H} ; \mathrm{J} ; \mathrm{K} ; \mathrm{L} ; \mathrm{M} ; \mathrm{N}$ & $\begin{array}{l}\text { - Incomplete or non-validated network } \\
\text { information }\end{array}$ & $\mathrm{D} ; \mathrm{E} ; \mathrm{I} ; \mathrm{K} ; \mathrm{N}$ \\
\hline \multirow[t]{2}{*}{$\begin{array}{l}\text { - Good knowledge and information on } \\
\text { infrastructure }\end{array}$} & $A ; C ; J ; L ; M$ & $\begin{array}{l}\text { - Poor structural and functional net- } \\
\text { work condition }\end{array}$ & $\mathrm{B} ; \mathrm{C} ; \mathrm{D} ; \mathrm{E} ; \mathrm{F} ; \mathrm{G} ; \mathrm{I} ; \mathrm{N}$ \\
\hline & & $\begin{array}{l}\text { - Lack of compatibility between infor- } \\
\text { mation systems }\end{array}$ & $A ; C ; E ; I ; J ; K ; M$ \\
\hline Opportunities & & Threats & \\
\hline $\begin{array}{l}\text { - Portuguese regulation and other legal } \\
\text { requirements related with IAM }\end{array}$ & $\mathrm{A} ; \mathrm{B} ; \mathrm{C} ; \mathrm{D} ; \mathrm{E} ; \mathrm{F} ; \mathrm{G} ; \mathrm{H} ; \mathrm{l} ; \mathrm{K} ; \mathrm{L} ; \mathrm{N}$ & $\begin{array}{l}\text { - The need for increasing tariffs due to } \\
\text { regulation }\end{array}$ & $\mathrm{A} ; \mathrm{C} ; \mathrm{D} ; \mathrm{E} ; \mathrm{F} ; \mathrm{G} ; \mathrm{H} ; \mathrm{l} ; \mathrm{J} ; \mathrm{K} ; \mathrm{N}$ \\
\hline - Funding access & $\mathrm{C} ; \mathrm{D} ; \mathrm{E} ; \mathrm{F} ; \mathrm{G} ; \mathrm{H} ; \mathrm{I} ; \mathrm{J} ; \mathrm{K} ; \mathrm{L} ; \mathrm{M}$ & $\begin{array}{l}\text { - Economic crisis and financial } \\
\text { restrictions }\end{array}$ & $\mathrm{B} ; \mathrm{E} ; \mathrm{I} ; \mathrm{K} ; \mathrm{L} ; \mathrm{M} ; \mathrm{N}$ \\
\hline \multirow{3}{*}{$\begin{array}{l}\text { - IAM approaches and supporting } \\
\text { technologies }\end{array}$} & $\mathrm{B} ; \mathrm{C} ; \mathrm{D} ; \mathrm{E} ; \mathrm{I} ; \mathrm{J} ; \mathrm{K} ; \mathrm{L} ; \mathrm{M} ; \mathrm{N}$ & - Population dynamics & $D ; J ; K ; L ; M$ \\
\hline & & $\begin{array}{l}\text { - Illegal connections in wastewater } \\
\text { systems }\end{array}$ & $\mathrm{F} ; \mathrm{G} ; \mathrm{H} ; \mathrm{I} ; \mathrm{K} ; \mathrm{L} ; \mathrm{N}$ \\
\hline & & - Climate changes & $C ; K ; L ; M$ \\
\hline
\end{tabular}

strategic objectives selected by the majority of the utilities are: "Adequacy of the service provided", "Service management sustainability" and "Environmental sustainability", reflecting concerns with the service provision and sustainability. Table 2 highlights the main relevant SWOT aspects identified by these utilities and provides a basis for scenario definition at a tactical level. To illustrate, the identified threat "Illegal connections in wastewater systems" was considered a basis to define assessment scenarios like those presented in Section 4.3.3.

Selected strategies are summarised in Figure 5. The strategies considered by the highest percentage of utilities are "promotion of proactive rehabilitation practices" (41\%) and "improvement of information management" (52\%), highlighting the importance of proactivity and information in IAM planning.

\subsection{Description of selected cases}

The tactical level of planning is highly case dependent. As previously referred to, since the cases studied cover a broad variety of situations, this section describes only the two systems for which results of the several supporting tools and methods applied are presented.

Águas de Coimbra is a municipal utility responsible for the management of water and wastewater services. The geographical area of $320 \mathrm{~km}^{2}$ corresponds to the entire municipality and serves 148,443 inhabitants. The wastewater service coverage is around $96 \%$, the total sewer system length is about $1070 \mathrm{~km}$, from which $235 \mathrm{~km}$ are stormwater sewers, and has 37 pumping

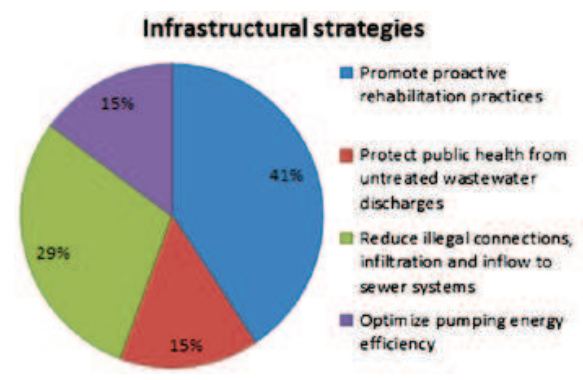

stations. Wastewater is treated in a WWTP not operated by the utility. The subsystem A.9, analysed in detail, comprises $488 \mathrm{~km}$ of sewers and 18 pumping stations.

SMAS Oeiras e Amadora is a municipal public utility responsible for the management of water and wastewater services of two municipalities, with a total area of $70 \mathrm{~km}^{2}$ serving 350,000 inhabitants. One municipality has an extension of $812 \mathrm{~km}$ of sewers, five pumping stations and 32,568 manholes, while the other has $435 \mathrm{~km}$ of sewer length and 15,472 manholes. The total length of sewers in both municipalities is $1248 \mathrm{~km}$, being mostly separate. Wastewater is treated in a WWTP not operated by the utility. The separate subsystem analysed in detail comprises 3.4 $\mathrm{km}$ of domestic sewer length, 256 service connections serving 4214 inhabitants, $3.5 \mathrm{~km}$ of storm sewers draining about 12.4 $\mathrm{hm}^{2}$. The main problems identified included high $\mathrm{I} / \mathrm{I}$ flows and poor structural condition. Taking into account the high I/I flows, SMAS Oeiras e Amadora carried out a monitoring survey in the selected subsystem. This survey aimed to calibrate the mathematical model, to quantify $\mathrm{I} / \mathrm{I}$ in order to assess its effect on the domestic sewer system performance as well as to identify solutions to maintain adequate performance levels (Camacho et al., 2012).

In order to proceed with the tactical planning both utilities initially identified available data and information gaps, namely in GIS, billing systems, complaints systems, work orders, costs, monitoring systems, mathematical models, CCTV inspection, performance indicators and accounting information.

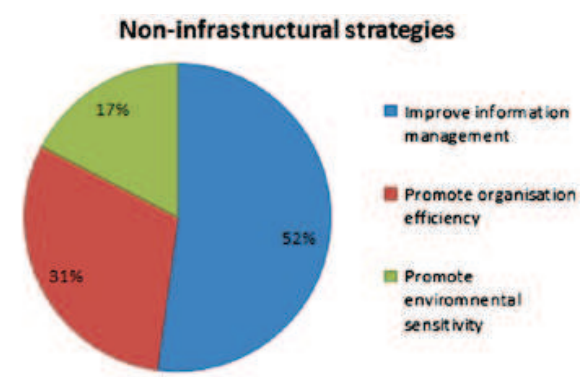

Figure 5. Strategies - percentage of selection by the fourteen wastewater utilities. 


\section{Results and discussion}

\subsection{Overview}

The cases studied by the fourteen utilities cover a broad variety of situations, leading to distinct paths and detail of analysis in the tactical planning process. Utilities used diverse tools and methods for analysis, both from the AWARE-P portfolio (PI, IVI and PLAN), as previously described in Section 2.2, and from other complementary technical approaches such as monitoring, mathematical modelling and CCTV inspections. The AWARE-P software provides an integration of all the obtained results for planning purposes through the PLAN tool.

In accordance with the AWARE-P methodology and in line with the strategic assessment system and strategies defined, both Águas de Coimbra and SMAS Oeiras e Amadora established the respective tactical assessment frameworks (Table 3 ) as their basis for decision making. They started by defining their objectives, corresponding assessment criteria and, subsequently, the metrics with respective reference values for classification and targets for the planning horizon (stage i).

Utilities used tools from the AWARE-P software as well as complementary sewer systems engineering analysis tools. Results do not aim to follow the entire process in a specific case study. They are presented focusing on the use of the information provided by each tool and on their integration, at each tactical planning stage.

This section describes results from the application of the AWARE-P methodology, focusing on the tactical level, using the PLAN tool for planning sewer systems asset management in: decision on priority areas of analysis, diagnosis and decision on the best intervention alternatives.

\subsection{Decision on the priority area for analysis}

The case of Águas de Coimbra is presented to demonstrate the selection of the priority systems for detailed analysis (stage ii of the methodology) and was based on the PI (Section 2.2.2) and PLAN (Section 2.2.4) tools.

Águas de Coimbra divided the sewer system into 21 subsystems for a detailed analysis, according to the catchment areas associated to each WWTP. Assessment for each subsystem was based on the metrics presented in Table 3 and classification values established for the tactical level of planning, as presented in Section 2.2.4. The PLAN tool provided a ranking of the 21 subsystem classifications based on the metrics and reference values. The worst performing system is identified as A.9, described in Section 3.2 , since its global score of 1.38 is the lowest, therefore the one with the highest priority of intervention and selected for further detailed analysis (Figure 6).

In this subsystem the most serious problems, represented by the red code in Figure 6, are untreated sewer discharges at pumping stations, low energy efficiency in pumping stations, high levels of inflow and infiltration (I/I) flows and low levels of rehabilitation.

The methodology provided a comparison of the 21 subsystem evaluations based on the same criteria, allowing identification of the main problems and the selection of the subsystem whose problem resolution has a higher contribution for compliance with the strategic objectives of the utility. The AWARE-P tools provided Águas de Coimbra an objective-driven and standardized way to assess, integrate, compare and rank a significant number of subsystems, thus supporting its decision on selecting the priority area for further detailed analysis.

\subsection{Sewer system detailed analysis and diagnosis}

\subsubsection{Priority subsystem}

The case of SMAS Oeiras e Amadora is presented to demonstrate sewer system detailed analysis and diagnosis in a priority subsystem (stage ii). As in Section 4.2, the same methodology was applied to select the priority subsystem, described in Section 3.2, for carrying out a detailed analysis.

The detailed analysis and diagnosis performed by SMASOeiras e Amadora was based on results from diverse tools and methods, including engineering analysis tools (Section 2.2.1) such as system monitoring, mathematical modelling, CCTV inspection and the PI (Section 2.2.2), IVI (Section 2.2.3) and PLAN (Section 2.2.4) tools.

\subsubsection{System results from engineering analysis tools}

4.3.2.1. Monitoring. A rain gauge and two flow meters, located at the downstream sewers respectively in the domestic and in the stormwater system, were installed. The monitoring survey lasted one year, in order to record flows from both

Table 3. Tactical assessment metrics applied to the areas of analysis.

Tactical assessment metrics

\section{Águas de Coimbra}

A_C1 - Infrastructure value index (ratio between actual and replacement values) $(-)$

A R2 - Sewer collapses (n. ${ }^{\circ} /(100 \mathrm{~km} /$ year))

A_R3 - Percentage of critical sewers length (high risk of failure) (\%)

A_P4 - Percentage of sewer length where shear stress is above $4 \mathrm{~N} / \mathrm{m}^{2}(\%)$

A_P5 - Percentage of sewer length where maximum velocity comply with legal requirements $(\%)$

A_P6 - Flooding from sewers related to the collection system (n. $\% / 1000$ service connections)

A_P7 - Percentage of WWTP having influent water quality control (\%)

A P8 - Energy efficiency in pumping stations $\left(\mathrm{kW} / \mathrm{m}^{3} .100 \mathrm{~m}\right)$

A_P9 - Percentage of illicit house connection inspection (\%/year)

A_P10 - I/I daily flow per unit sewer length $(\mathrm{I} /(\mathrm{day} / \mathrm{m}))$

A_P11 - Infrastructural knowledge and asset management index (-)

A_P12 - Flow measurement index for sewer systems (-)

A_C13 - Human, material and equipment resources used in the systems opera-

tion and maintenance $(€ / \mathrm{km} /$ year $)$
SMAS Oeiras e Amadora

N_C1 - Infrastructure value index (ratio between actual and replacement values) $(-\overline{)}$

N R2 - Percentage of sewer length having moderate risk of collapse (\%)

N_R3 - Percentage of sewer length having high risk of collapse (\%)

N_P4 - Percentage of sewer length where low velocities occur (prone to sedimentation) (\%)

N_P5 - Percentage of surcharged sewer length (\%)

N_P6 - Minimum dry weather capacity utilization (\%)

N_P7 - Maximum dry weather capacity utilization (\%)

N P8 - Proportion of minimum to the average dry weather daily flow (\%)

N_P9 - Proportion of maximum to the average dry weather daily flow (\%)

N_P10 - Minimum dry weather daily flow per unit sewer length $\left(\mathrm{m}^{3} /(\right.$ day.km)

N P11 - Maximum wet weather capacity utilization (\%)

N_P12 - Stormwater inflow proportion of dry weather (\%) 


\begin{tabular}{|c|c|c|c|c|c|c|c|c|c|c|c|}
\hline & 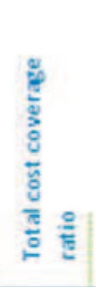 & 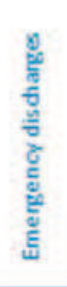 & 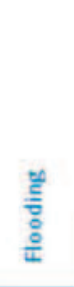 & 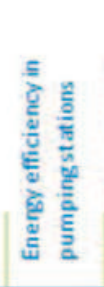 & 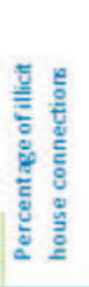 & 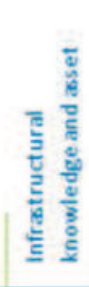 & 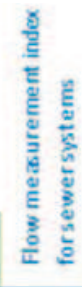 & 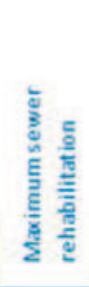 & 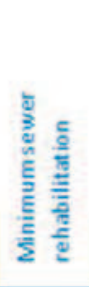 & 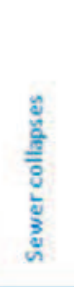 & $\begin{array}{c}2011 \text { kank } \\
\text { Hate? }\end{array}$ \\
\hline$\underline{A}$ & C & - & 0 & 0 & - & O & $\bullet$ & - & - & 0 & (it) $=17$ \\
\hline$\Delta .10$ & $C$ & - & O & O & - & P & $\bullet$ & - & 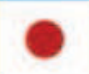 & ○ & $2 \pi=4$ \\
\hline$\Delta 11$ & 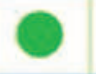 & $\bullet$ & 0 & O & - & C & $\bullet$ & O & & O & (ith $=6$ \\
\hline$\Delta .12$ & 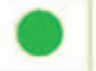 & - & O & 0 & - & O & - & - & 0 & 0 & (2.65 $=18$ \\
\hline An & 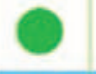 & - & O & O & - & & $\bullet$ & O & & 0 & $(25)=10$ \\
\hline A19 & 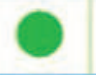 & - & 0 & O & - & O & $\bullet$ & O & & 0 & (it) $=14$ \\
\hline A.1s & 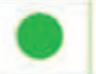 & - & ? & 0 & - & O & - & 0 & O & O & $270=16$ \\
\hline Ast & 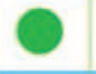 & - & O & 0 & - & O & - & 0 & 0 & 0 & 2301 \\
\hline$\underline{A x}$ & & • & ○ & O & - & O & - & 0 & & O & (26) $=19$ \\
\hline A.18 & 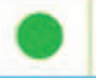 & - & ○ & 0 & - & ○ & $\bullet$ & 0 & & 0 & $1.96=6$ \\
\hline A.19 & & • & O & 0 & - & 0 & $\bullet$ & 0 & & O & $200=5$ \\
\hline$\Delta x$ & & - & O & O & ○ & O & $\bullet$ & 0 & & & $=20$ \\
\hline$\Delta .20$ & & - & O & 0 & - & O & $\bullet$ & 0 & & O & $=6$ \\
\hline$\Delta 21$ & & - & O & O & - & O & $\bullet$ & 0 & & 0 & $1.98=12$ \\
\hline$\underline{\Delta}$ & & - & O & ○ & ○ & O & $\bullet$ & 0 & & & $2.74=15$ \\
\hline$\underline{A}$ & & • & O & O & - & O & - & 0 & & O & $=11$ \\
\hline As & & - & O & 0 & ○ & O & $\bullet$ & 0 & & 0 & (1.9h $=6$ \\
\hline$\underline{A 6}$ & & - & O & O & - & O & $\bullet$ & 0 & 0 & 0 & $22 \pi=2$ \\
\hline$\underline{\prime \prime}$ & & - & 0 & O & - & O & - & O & & ○ & $17=13$ \\
\hline AI & & - & ( & O & - & O & - & (1) & 0 & 0 & $=: 40$ \\
\hline$\underline{A}$ & & • & 0 & & - & 0 & $\bullet$ & 0 & & O & $13=21$ \\
\hline
\end{tabular}

Figure 6. PLAN tool - Classification ranking of Águas de Coimbra subsystems.

dry and wet weather. About 52 rainfall events with distinct characteristics of volume, duration and intensities were recorded. From monitoring results in the domestic system, illustrated in Figure 7, it was observed that the maximum wet weather flow reached 36 times the average dry weather flow in the monitoring period. Monitoring results were essential to establish evaluation scenarios and to calculate the assessment metrics, namely regarding the minimum, average and maximum daily flows, in dry and wet weather, as well as the stormwater inflow volume in wet weather periods, in the domestic system. 


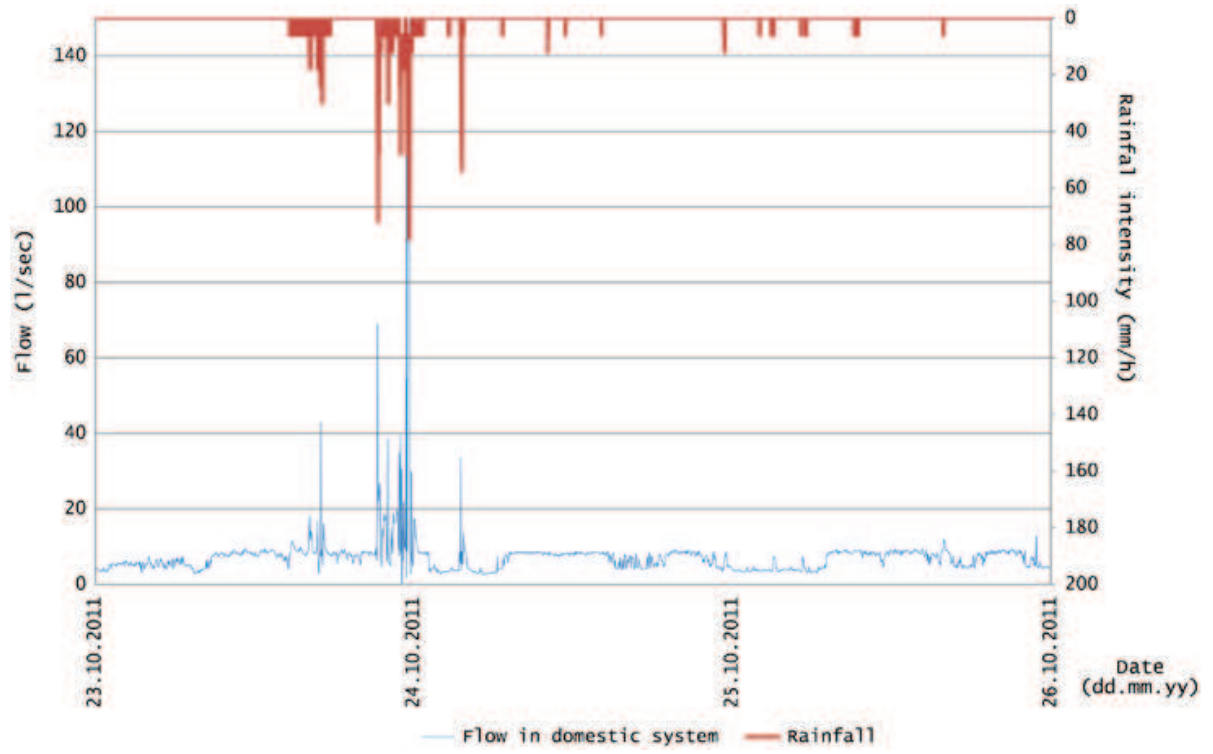

Figure 7. SMAS Oeiras e Amadora flow and rainfall measurement results in the selected subsystem.

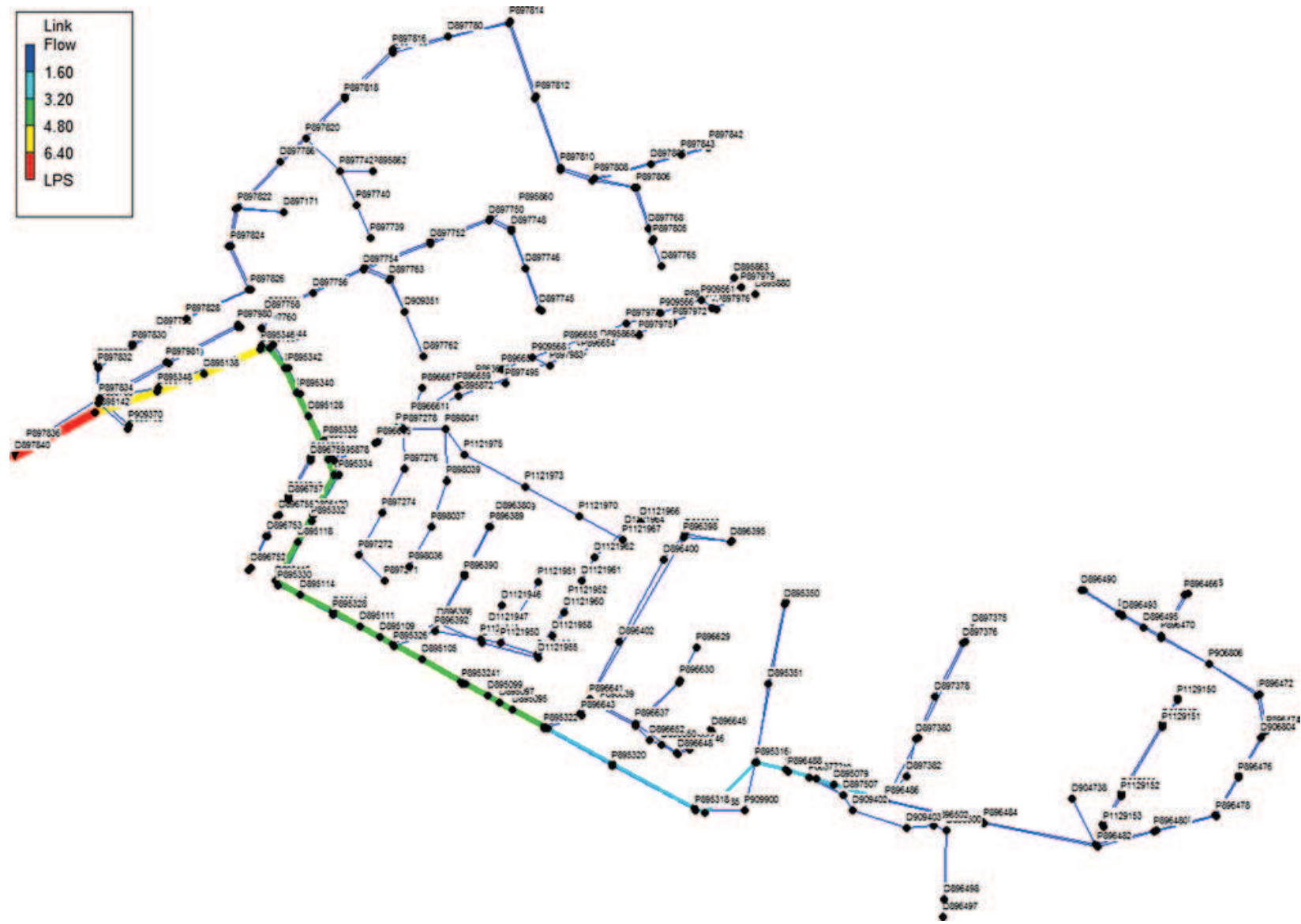

Figure 8. SMAS Oeiras e Amadora selected subsystem mathematical model (Camacho et al., 2012).

The results are analysed and discussed in Section 4.3.3., by assessing the performance metrics with the PI tool.

4.3.2.2. Mathematical modelling. To perform a system diagnosis at the tactical level and assess different scenarios for analysis, SMAS Oeiras e Amadora built a mathematical model of the separate sewer systems using the SWMM model (USEPA, 2010), including both the domestic and stormwater components. This model is presented in Figure 8 and was calibrated based on flow and rainfall data measurements from the survey previously described, considering as criteria the relative errors on peak discharge and on hydrogram volume below $10 \%$. 


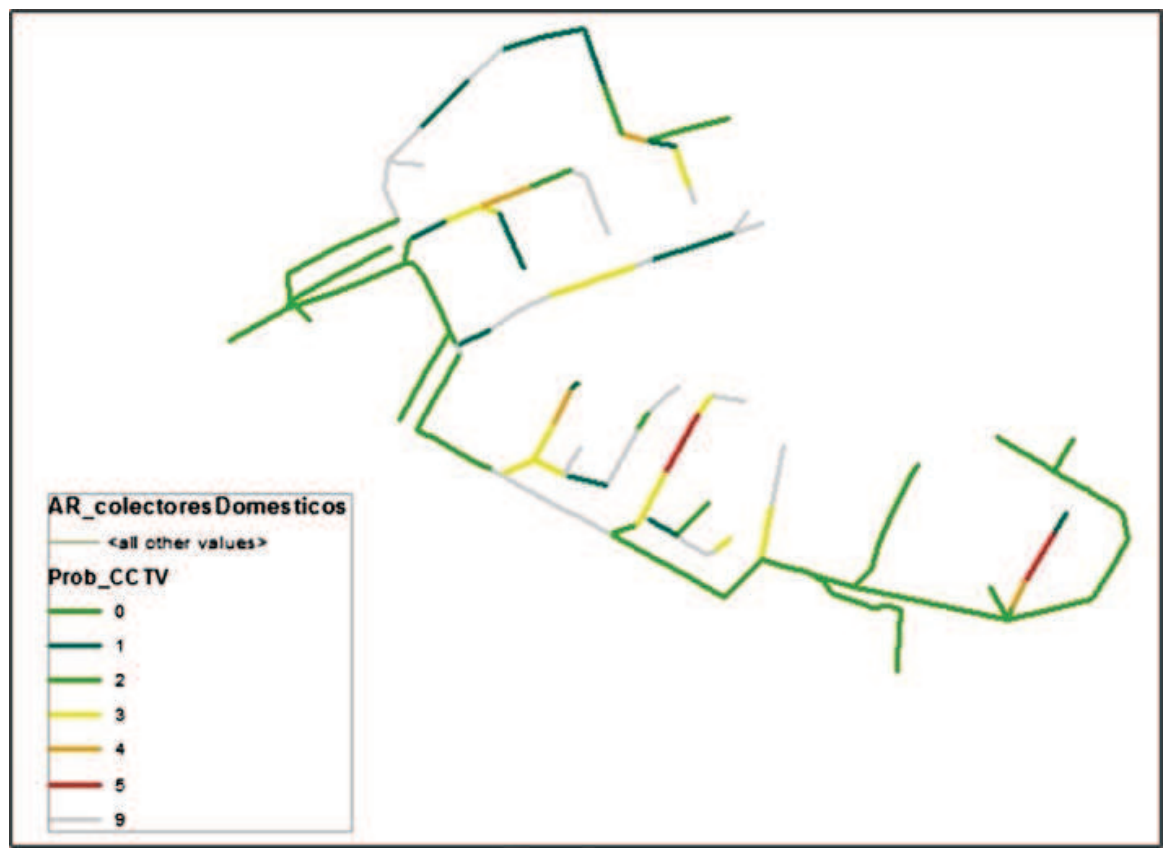

Figure 9. SMAS Oeiras e Amadora structural condition of domestic sewer system (Camacho et al., 2012).

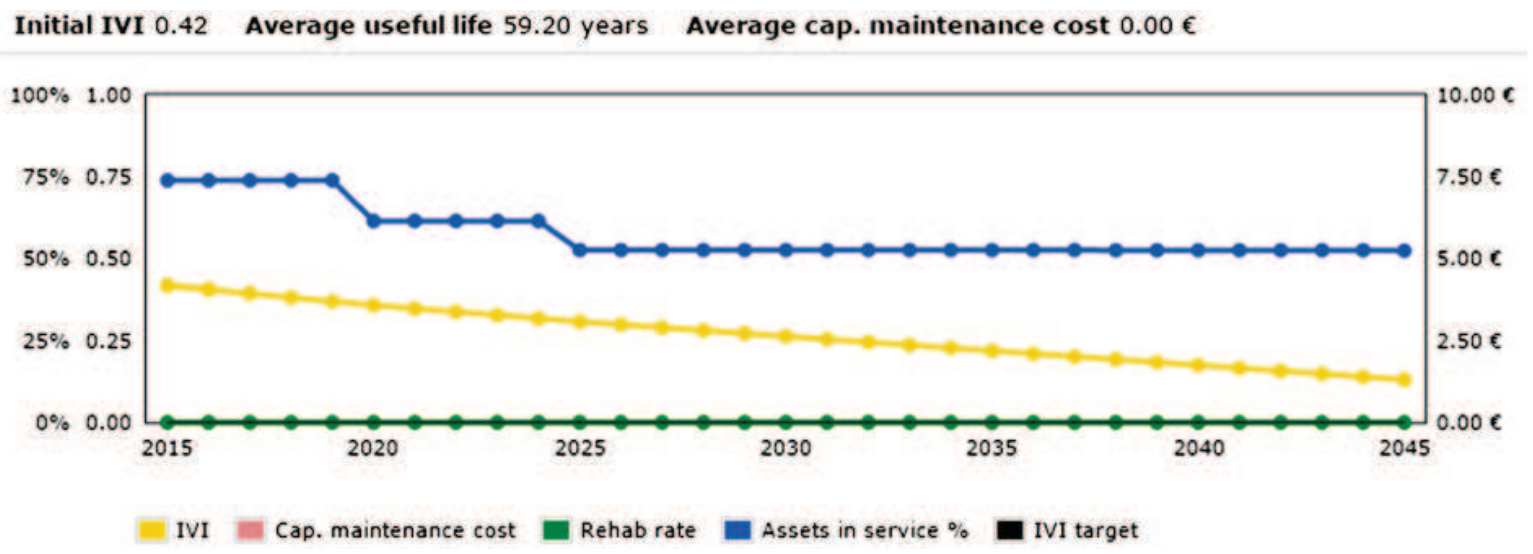

Figure 10. SMAS Oeiras e Amadora IVI evolution over the planning horizon.

To assess the effect of $\mathrm{I} / \mathrm{I}$ on the hydraulic performance of the system, a detailed study was carried out in the domestic system through the simulation of different scenarios for analysis, considering both dry and wet weather conditions. These scenarios correspond to load factors (If) of 1,20 and 50 relative to the dry weather hydrogram (Camacho et al., 2012) and were defined based on the domestic system monitoring results (Figure 7). The unit If corresponds to the system operation in dry weather. Modelling results were necessary to quantify the selected assessment metrics in the PI tool, and the results are analysed and discussed in Section 4.3.3.

4.3.2.3. CCTV inspection. As already referred to, to perform a system diagnosis at the tactical level SMAS Oeiras e Amadora carried out a CCTV inspection survey on the priority domestic subsystem selected, described in Section 3.2. SMAS Oeiras e Amadora followed the Water Research Centre method (WRc, 2001), presented in Section 2.2.2., to classify the sewer's structural condition for the domestic subsystem. Results presented in
Figure 9 (Almeida et al., 2011), show that most sewers have a low probability of collapse. However it is possible to identify sewers likely to collapse in the near future or where collapse is imminent. Inspection information was essential to quantify the selected assessment metrics with the PI tool whose results are analysed and discussed in Section 4.3.3.

\subsubsection{Assessments through AWARE-P tools}

4.3.3.1. PI tool - assessment results. SMAS Oeiras e Amadora applied the PI tool using the defined assessment system, presented in Table 3 that includes risk (R), cost (C) and performance $(P)$ metrics.

Risk metrics. The risk metrics N_R2 and N_R3, in Table 3, were calculated as described in Section 2.2.2. The probability of sewer collapse was estimated based on its structural condition assessed by CCTV inspection, as described in Section 4.3.2. It was a system manager's decision to classify the consequences of sewer collapse using their knowledge from operating the system. 


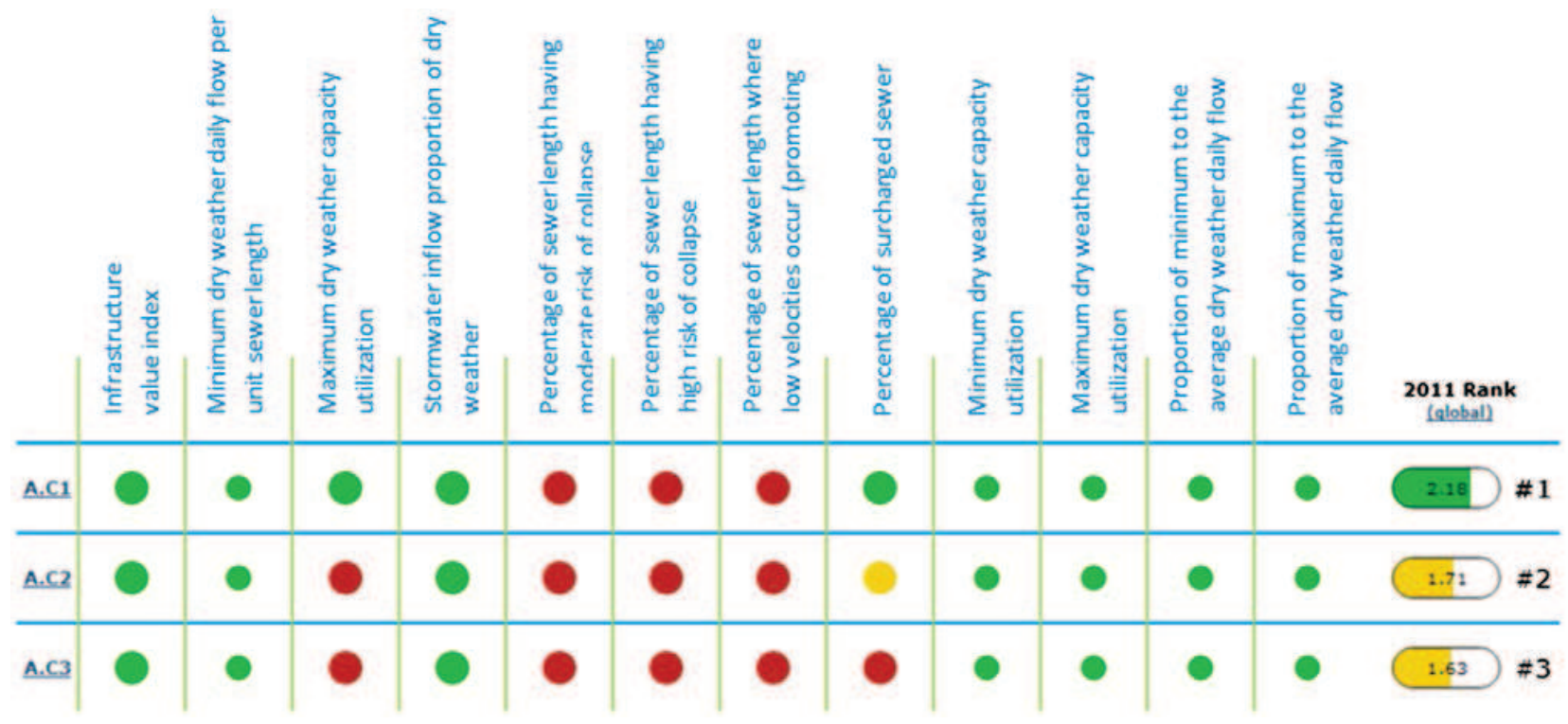

Figure 11. SMAS Oeiras e Amadora scenarios assessment of the current domestic sewer system (Camacho et al., 2012).

Risk metrics N_R2 and N_R3 are expressed as the percentage of the length of sewers having moderate (yellow) and high (red) levels of risk, respectively (Figure 2 and Figure 9).

Risk metrics were classified in the PI tool, according to the reference values defined by SMAS Oeiras e Amadora based on their experience, knowledge and requirements established for the systems' operation.

Cost metrics. An adequate metric to assess infrastructural sustainability, according to DWA (2006), is the relative value of an infrastructure, named as Infrastructural Value Index (IVI) by Alegre (2007). Using IVI, as presented in Section 2.2.3, SMAS Oeiras e Amadora calculated the cost metric IVI (N_C1 in Table 3) for the current situation and for its evolution over 20 years, the IAM plan horizon, if no rehabilitation is carried out. It is presented in Figure 10.

This figure shows for the current situation an IVI of 0.47 , close the recommended value, as presented in Section 2.2.3. This means that the infrastructure is mature, about $75 \%$ of the sewers are in service. If no rehabilitation is carried out, in the long-term, it is expected that the IVI would reach values close to 0.2 , meaning that only $50 \%$ of the sewers will be in service and system functioning will be compromised. The IVI assessment is to be updated and revised taking into account the rehabilitation practices implemented.

Performance metrics. Based on the monitoring results (Section 4.3.2), SMAS Oeiras e Amadora selected three evaluation scenarios for the domestic sewer system, corresponding to the following situations:

A.C1 - dry weather situation, corresponding to a unit If;

A.C2 - wet weather condition with a If of 20 and

A.C3 - wet weather condition considering a If of 50 .

Performance metrics, defined by SMAS Oeiras e Amadora in Table 3, were calculated using the PI tool and based on the sewer system information, as described in Section 2.2.1. The metrics N_P4 and N_P5 required mathematical modelling results and metrics N_P6 to N_P12 required monitoring data, as described in Section 4.3.2.
4.3.3.2. PLANtool-globalassessmentandvisualization. SMAS Oeiras e Amadora used the ability provided by the PLAN tool to compare assessments of the three established operating scenarios described (A.C1, A.C2 and A.C3).

The assessment results of all the metrics are presented in Figure 11 using the colour-coded classification, as described in Section 2.2.4. It is possible to identify aspects that remained unchanged between scenarios, particularly those related to the structural component and with the groundwater infiltration. Globally, the system performance decreases with the increase in the loading factor, with the scenario A.C3 the worse classified. From this, the utility may establish a classification level as a trigger for intervention in the system.

It is possible to conclude that the rehabilitation activity in the system is adequate (N_C1), however there are still problems regarding risk of sewer collapse (N_R2 and N_R3). Infiltration in the system is acceptable (N_P10) since it does not cause hydraulic problems (N_P6 and N_P7) or excessive costs to the utility (N_P8 and N_P9) (Camacho et al., 2012).

For the wet weather scenarios (A.C2 and A.C3) stormwater reaches the domestic system (N_P11), causing problems of hydraulic capacity, aggravated by an increased load factor (N_P5) and reaching unacceptable levels. However, the impact in terms of treatment costs remains acceptable (N_P12).

With respect to the three scenarios, the system presents problems related to excessively low velocities (N_P4) providing conditions for the occurrence of odours and sedimentation. This problem is more serious in dry weather (A.C1), with a slight improvement in wet weather (scenarios A.C2 and A.C3), since stormwater inflows to the domestic system increase flow velocity in the sewers.

The AWARE-P tools provided SMAS Oeiras e Amadora with an objective-driven and standardized way to assess and integrate relevant information from diverse sources, thus supporting a detailed analysis, diagnosis as well as scenarios assessment and comparison. As referred to in Section 2.2.1, uncertainty is incorporated in AWARE-P through the definition of the classification 


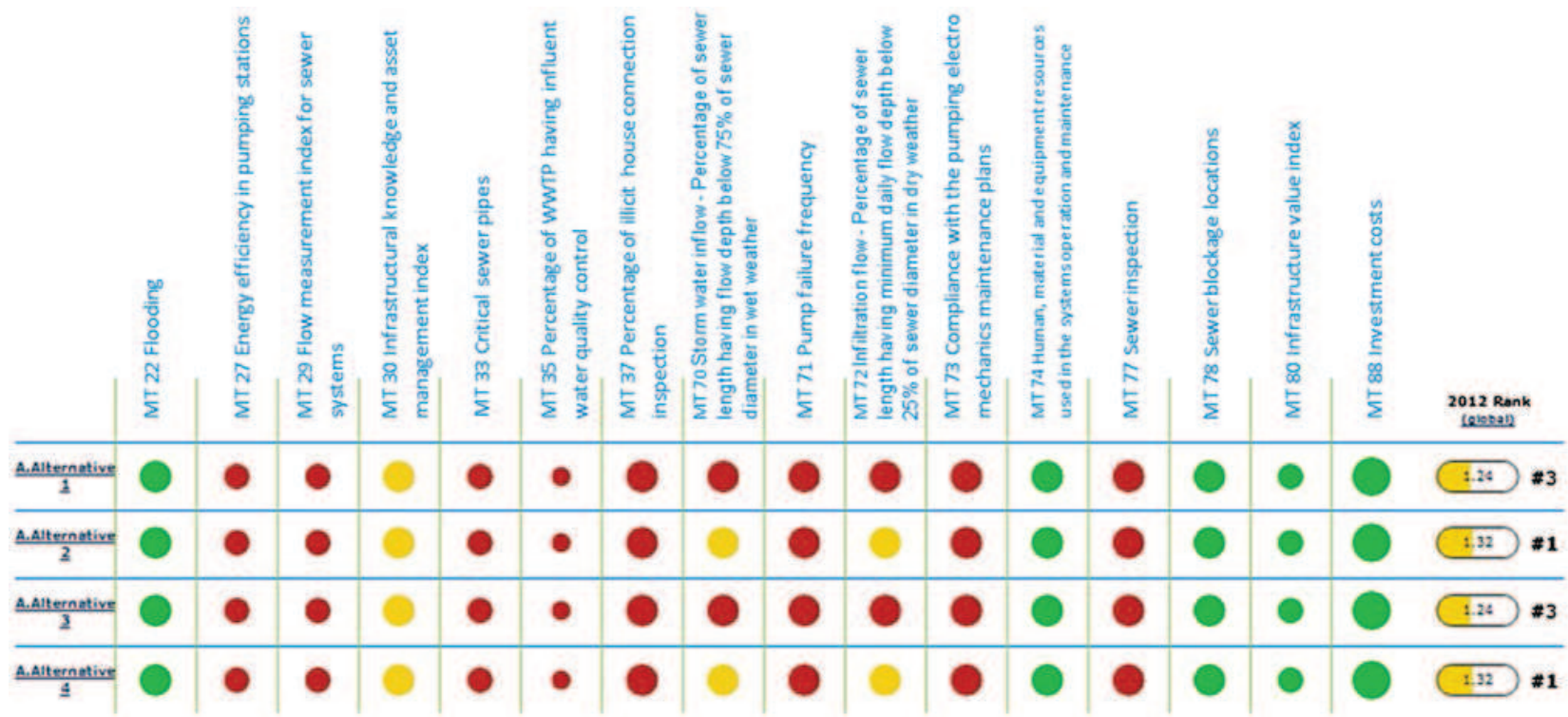

Figure 12. Águas de Coimbra alternative assessment ranking for the current situation (2012).

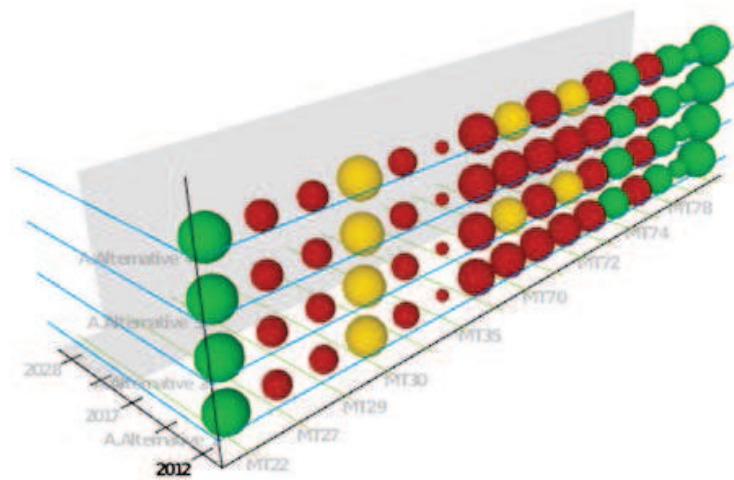

Figure 13. Águas de Coimbra alternatives assessment over time.

functions for the metrics and the assessment scenarios establishment. This global assessment supported identification of several system-driven solutions. These included infrastructural solutions, such as replacement or relining of sewers having a nonacceptable risk of collapse and identification and elimination of illicit connections. They also include non-infrastructural solutions such as the development of a sewer cleaning plan.

\subsection{Decision on the best intervention alternative}

The case of Águas de Coimbra is presented to demonstrate the application of the PLAN (Section 2.2.4) tool to support the decision on the best intervention alternative to be implemented by ranking alternative assessments, based on the defined metrics.

As in Section 4.3, Águas de Coimbra carried out a detailed analysis and diagnosis of the current situation (stage ii of the methodology) in the selected area of analysis, using the assessment metrics presented in Table 3 and associated reference values. The diagnosis allowed the identification as the main problem's high $\mathrm{I} / \mathrm{I}$ flows in the domestic system and low energy efficiency in pumping.

Several system-driven solutions were analysed (stage iii) to solve or mitigate the problems identified in the diagnosis. The

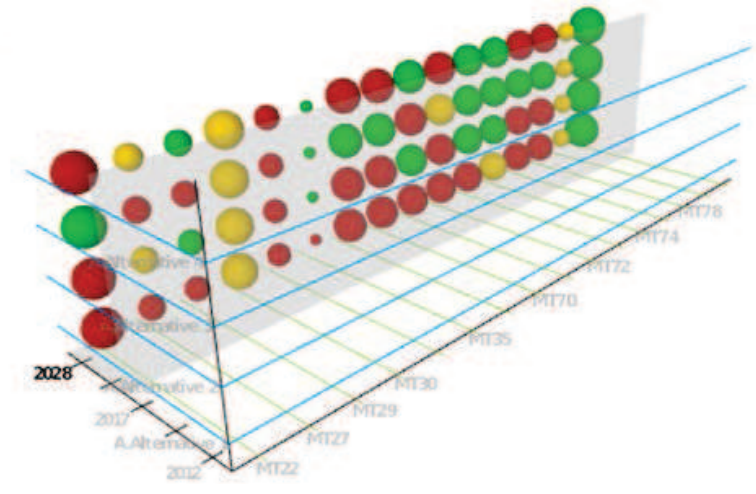

best solution of each type (infrastructural, e.g. replacement, or non-infrastructural, such as operation and maintenance related) was identified as an alternative, as well as the status quo situation, as follows:

Alternative 1: Status quo - to keep the existing network and the current reactive capital maintenance policy.

\begin{abstract}
Alternative 2: Intervention in the pumping station - to replace the existing group with a new, more energy efficient, one; to measure the energy consumed only by the group; to install a flow meter; to ensure proper maintenance.
\end{abstract}

Alternative 3: Inflow and infiltration surveys - to carry out $\mathrm{l} / \mathrm{I}$ surveys for detection of illicit connections.

Alternative 4: Construction of a new pumping station.

The assessment of the four alternatives was carried out for the current situation (2012), 5-year planning horizon and 20-year analysis horizon. Figure 12 presents the results ranking the four alternatives using the selected metrics for the current situation. Figure 13 presents the assessment both for the current situation and considering a 20-year analysis horizon.

The classification of the majority of metrics does not change among alternatives both for the current situation and over time. The main changes are related with $\mathrm{I} / \mathrm{I}$ metrics. Both Alternatives 
2 and 4 provide improvement in energy efficiency, pump failures and O\&M costs while Alternative 3 will improve the frequency of flooding and blockage as well as O\&M costs as compared with Alternative 1.

Based on the assessment results for each alternative, the PLAN tool provides the ranking of alternatives, supporting Águas de Coimbra in the decision of the best intervention alternative. For the current situation, both Alternatives 2 and 4 are equally classified in first place. However, Alternative 3 was the one selected to implement in this area of analysis (stage iv) since it provides higher improvements in the system in the long-term. This is presented in Figure 13 where, following the colour-coding, metrics classified as good (green) in 2012 change to deficient (red) in the long-term (2028).

The AWARE-P tools provided Águas de Coimbra an objective-driven and standardized way to assess, integrate, compare and rank several system-driven solutions to solve or mitigate the problems identified in the diagnosis. The evaluation is based on the same criteria, allowing identification of the alternatives with a higher contribution for compliance with the strategic objectives of the utility. Since Águas de Coimbra implemented the AWARE-P approach for development of the IAM plan, it was assured that the selected intervention alternative is aligned with the strategic and tactical objectives and, consequently will contribute in the mid- and long-terms to their compliance.

\section{Conclusions}

The AWARE-P approach aims to support urban water utilities in implementing a coherent, structured procedure for IAM. Planning IAM requires many inputs from different sources and analysis of several partial processes. The approach implementation may be facilitated by the AWARE-P software consisting of an innovative proposal in IAM planning analysis, as it makes available on an advanced technology platform the best tools for visualizing, diagnosing and evaluating any given urban water system, through a portfolio of performance, risk and cost models, at both global and detail levels, for the short-, medium- and long-terms.

The paper summarises the current experience in the application of this approach by fourteen wastewater utilities, focusing on two particular case studies at tactical planning level, by presenting the main representative applications and results achieved.

Implementation of this methodology requires considerable effort and resources, particularly in cases where there is insufficient integration between different organizational levels, poor availability or quality of data, limitations in existing information systems or financial constraints. However, there is good evidence that this approach provides a standardized and flexible IAM planning framework that can be successfully used to tackle utility problems assuring that the interventions implemented in the systems are aligned with the strategic and tactical objectives of the utilities, thus contributing to their compliance in the midand long-term.

\section{Acknowledgements}

The authors acknowledge the contributions from all utilities, organizations and individuals that took part in the projects AWARE-P and iGPI as well as to European Financial Mechanism (EEA Grants) for their support to the AWARE-P project. Very special thanks are due to the utilities - Águas de Coimbra and SMAS Oeiras e Amadora - for the collaboration and agreement in the use of their information and results.

\section{References}

Alegre, H., 2007. Water infrastructure asset management, Research Program, Series. Thesis and Research Programmes, LNEC, Lisbon, ISBN: 978-9-72492134-1 (385 p.) (in Portuguese).

Alegre, H., et al., 2010. Guia de Avaliação da Qualidade dos Serviços de Águas

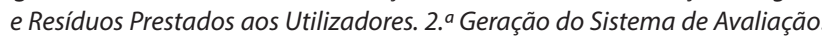
ERSAR/LNEC, Guia Técnico 19, Série Guias Técnicos. Lisbon: ERSAR Publishing. ISBN: 978-989-8360-11-3.

Alegre, H., et al., 2011. Integrated approach for infrastructure asset management of urban water systems. In: International Water Association 4th Leading Edge Conference on Strategic Asset Management, 27-30 September, Mülheim an der Ruhr, Germany. London: IWA Publishing.

Alegre, H., Vitorino, D., and Coelho, S.T., 2014. Infrastructure value index: A powerful modelling tool for combined long-term planning of linear and vertical assets. Procedia Engineering, 89, 1428-1436.

Almeida, M.C. and Cardoso, M.A., 2010. Infrastructure Asset management of Wastewater and Stormwater Services. An aproach based on rehabilitation (in Portuguese). Technical Guide n.17. Lisboa, Portugal: ERSAR, LNEC, IST, .

Almeida, M.C., Leitão, J.P., and Silva, M.S., 2011. Avaliação da condição estrutural de colectores: inspeção visual com CCTV, requisitos e uso de dados. In: ENEG 2011 - Encontro Nacional de Entidades Gestoras de Água e Saneamento, 22 November, Santarém, Portugal. Lisbon: APDA Publishing.

Ana, E.V. and Bauwens, W., 2010. Modeling the structural deterioration of urban drainage pipes: the state-of-the-art in statistical methods. Urban Water Journal, 7 (1), 47-59.

Baur, R. and Herz, R., 2001. Selective inspection planning with aging forecast for sewer types. In: Proceedings 2nd IWA World Water Congress, 15-19 October, Berlin, Germany. London: IWA Publishing

Brown and Humphrey, 2005. Asset management for transmission and distribution. Power and Energy Magazine, IEEE, 3 (3), 39-45. doi:10.1109/ MPAE.2005.1436499.

Burns, P., Hope, D., and Roorda, J., 1999. Managing infrastructure for the next generation. Automation in Construction, 8 (6), 689.

Camacho, P., et al., 2012. A aplicação da metodologia AWARE-P a um sistema de saneamento nos SMAS OEIRAS AMADORA. $15^{\circ}$ Encontro Nacional de Saneamento Básico, ENASB 2012, 10-12 October, Évora, Portugal. Lisbon: APESB Publishing.

Cardoso, M.A., et al., 2012. Urban water infrastructure asset management - A structured approach in four water utilities. Water Science and Technology, 66 (12), 2702-2711.

Coelho, S.T., Vitorino, D., and Alegre, H., 2013. AWARE-P: a system-based software for urban water IAM planning. IWA LESAM 2013, 10-12 September, Sydney, Australia. Sydney: AWA Publishing.

CEN, 2008. EN 752:2008. Drain and sewer systems outside buildings. European Standardization Committee, Article History 24 November 2007. Brussels: CEN Publishing.

DWA, 2006. DWA-M 143E:2005. Rehabilitation of drainage systems outside buildings. Part 14: Rehabilitation strategies. DWA German Association for Water, Wastewater and Waste. Hennef: DWA Publishing. ISBN: 978-3939057-26-0.

Fenner, R.A., 2000. Approaches to sewer maintenance: A review. Urban Water, 2, 343-356.

Halfawy, M.R., 2008. Integration of municipal infrastructure asset management processes: challenges and solutions. Journal of Computing in Civil Engineering, 22 (3), 216-229.

INGENIUM \&, IPWEA, 2006. International. infrastructure management. manual, vs 3.0. Sydney, Australia: Association. Local Govmt Eng. NZ Inc (INGENIUM) and Inst. Public Works Eng. of Australia (IPWEA).

ISO, 2007a. ISO 24510:2007(E) Activities relating to drinking water and wastewater services - Guidelines for the assessment and for the improvement of the service to users. Geneva: ISO Publishing.

ISO, 2007b. ISO 24511:2007(E) Activities relating to drinking water and wastewater services - Guidelines for the management of wastewater utilities and for the assessment of wastewater services. 
ISO, 2007c. ISO 24512:2007(E) Activities relating to drinking water and wastewater services - Guidelines for the management of drinking water utilities and for the assessment of drinking water services.

ISO, 2012a. ISO/CD 55000.2 Asset management - Overview, principles and terminology.

ISO, 2012b. ISO/CD 55001.2 Asset management — Management systems Requirements.

ISO, 2012c. ISO/CD 55002.2 Asset management Guidelines for the application of ISO 55001.

Leitão, J.P., et al., 2014. Moving urban water infrastructure asset management from science into practice. Urban Water Journal, doi:10.1080/157306 2X.2014.939092.

Marques, M.J., et al., 2011. Rehabilitation in Oeiras \& Amadora: a practical approach. In: International Water Association 4th Leading Edge Conference on Strategic Asset Management, 27-30 September, Mülheim an der Ruhr, Germany. London: IWA Publishing.

Matos, R., et al., 2003. Performance Indicators for Wastewater Services. London: IWA Publishing.

OECD, 2007. Infrastructure to 2030 - Vol. 2. Mapping Policy for Electricity, Water and Transport. Paris: OECD Publishing.
Price, R.K. and Vojinovic, Z., 2011. Urban hydroinformatics: data, models and decision support for integrated urban water management. London: IWA Publishing. ISBN: 978-18-4339-274-3.

Sægrov, S., ed., 2005. CARE-W - Computer Aided Rehabilitation for Water Networks. EU project: EVK1-CT-2000-00053., London: IWA Publishing.

Sægrov, S. , ed., 2006. CARE-S - Computer Aided Rehabilitation for Sewer and Stormwater Networks. London: IWA Publishing.

Sneesby, A., 2010. Sustainable infrastructure management program learning environment (SIMPLE). Sustainable Infrastructure and Asset Management Conference, Australian Water Association. 23-24 November 2010, Sydney, Australia (CD). St Leonards: AWA Publishing.

USEPA, 2010. Storm Water Management Model - User's Manual. EPA/600/R-05/040. Retrieved from:, http://www.epa.gov/nrmrl/wswrd/ $\mathrm{wq} / \mathrm{models} / \mathrm{swmm}$.

Vanier, M.R., 2001. Why industry needs asset management tools. Journal of Computing in Civil Engineering, 15(1), 35-43.

Walski, T.M., et al., 2007. Wastewater collection system modelling and design. Exton, PA: Bentley Institute Press. ISBN: 978-1-934-49303-8.

WRc, 2001. Sewer rehabilitation manual. 4th ed. Swindon: Water Research Council. 